\title{
Denture Base Composites: Effect of Surface Modified Nano- and Micro-Particulates on Mechanical Properties of Polymethyl Methacrylate
}

\author{
Touraj Nejatian ${ }^{1}$, Neil Nathwani ${ }^{1}$, Louise Taylor ${ }^{2}$ and Farshid Sefat ${ }^{2,3, *(\mathbb{D})}$ \\ 1 Eastman Dental Institute, University College London, London WC1X 8WD, UK; tnejatian@yahoo.com (T.N.); \\ n.nathwani@ucl.ac.uk (N.N.) \\ 2 Department of Biomedical and Electronics Engineering, School of Engineering, University of Bradford, \\ Bradford BD7 1DP, UK; 1.woolley@bradford.ac.uk \\ 3 Interdisciplinary Research Centre in Polymer Science \& Technology (IRC Polymer), University of Bradford, \\ Bradford BD7 1DP, UK \\ * Correspondence: F.Sefat1@Bradford.ac.uk
}

Received: 19 November 2019; Accepted: 3 January 2020; Published: 9 January 2020

check for updates

\begin{abstract}
The most commonly used denture base material, polymethyl methacrylate, lacks ideal mechanical properties, which are reflected in its relatively high failure rate. Several methods have been explored to reinforce the material and reduce the cost of denture repair and replacement. In this study, various surface modified filler particles at different concentrations were dispersed in conventional and high-impact denture base materials and tested for their improvement in mechanical properties. Inorganic filler particles were coated with different silane coupling agents using an ultrasonic device. The particulates were dispersed in the resin and the composites polymerised through an innovative dual-cure technique. Charpy impact test, single-edge notch three-point bend fracture toughness test and Biaxial Flexural Strength (BFS) were performed on the specimens. The results showed that mechanical properties of the denture base resin can be improved by incorporating filler particles; however, the surface characteristics, quantity and level of dispersion of the particles play critical role in the mechanical behaviour of the composites. The results of this study are a promising step towards developing more fracture-resistant denture base materials.
\end{abstract}

Keywords: polymethyl methacrylate; flexural strength; impact strength; fracture toughness; filler particle; silane treatment

\section{Introduction}

The most common used material for making dentures is polymethyl methacrylate (PMMA) owing to several advantages including accurate fits, stability within the oral environment, cost-effectiveness and simple laboratory and clinical manipulation [1]. Despite the common use of PMMA, two-thirds of dentures break within three years of their use [2,3]. Results from Darbar et al., 1994 [4], reported 33\% of repairs were due to debonding of the teeth, $29 \%$ due to midline fractures and the remaining $38 \%$ due to other types of fracturing. The transverse strength of denture base materials is an indicator of performance [5,6] related to flexural fatigue and impact fracture [7].

Improvement of PMMA dentures would require four aspects to be considered, dependent on the etiology of the fracture: (a) maintaining mechanical characteristics through corrective surgery of anatomical abnormalities, to improve denture fit and balance the occlusion [8]; (b) optimizing chemical structure whilst forming the denture by modifying the packing and processing techniques $[9,10]$; (c) improving adhesion between teeth and denture base [11]; (d) modifying the composition chemically 
by replacing brittle polymers with adding rubber particles [12], adding fibres, metal inserts and other particles [13] polyamides, epoxy resin, PVA, polycarbonate, polyurethane and nylon [14-16].

Conventional PMMA denture base material is mainly composed of pre-polymerised beads (PMMA powder) and monomer (Methyl Methacrylate, MMA). Methylmethacrylate monomers (Figure 1), using the process of free radical addition polymerization, make polymethylmethacrylate (PMMA). This process includes the sequence of activation, initiation, propagation and termination. Depending on the activation process, the materials are classified as heat-cured, cold-cured, light-activated or microwave-cured acrylic resin.

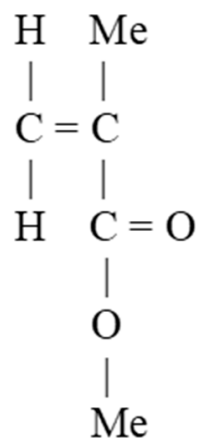

Figure 1. Methylmethacrylate molecular structure (Me stands for $-\mathrm{CH} 3$ ).

PMMA undergoes addition polymerization in which free-radical polymerization reactions occur with molecules containing carbon double bonds. This is a reaction without a by-product accelerated by heat, light or chemicals. The reaction is initiated by a free radical made by one of these initiators. The initiation stage is followed by the propagation stage in which other monomers bound to the free radical speedily shift the free electron to the end of the chain. The chain continues growing until free radicals are terminated. The termination stage can take place in several ways. Another material may react with a free radical can reduce the initiation or increase the rate of termination. The degree of monomer conversion depends on the method and condition of activation such as light activation versus dual activation, the distance from the light source and preheating prior to light activation. Decreasing the initiation rate retards polymerization and increasing the rate of termination reduces the degree of polymerization and the molecular weight of the final polymer. The polymerisation is inhibited by oxygen [17], hydroquinone and eugenol. Therefore, a small amount of hydroquinone is commonly presented in the monomer to increase the shelf life.

Conventional denture base materials are heat-cured and usually supplied as a powder and liquid. Composition of the powder included beads or granules of poly methyl methacrylate, benzoyl peroxide as an initiator, pigment/dyes, opacifiers-titanium/zinc oxides, plasticizer dibutyl phthalate and synthetic fibres-nylon/acrylic. Components of the liquid are methyl methacrylate monomer, hydroquinone and cross-linking agent-ethylene glycol dimethacrylate. Good physical properties are achieved by the high degree of polymerization, but the adaptation to the tissues is poor due to polymerization contraction, thermal contraction and the strain accompanying stress release during deflasking. Although heat-activated acrylic resins have certain flaws, they are still one of the most common used materials for denture fabrication.

Another type of heat-cure resin is rapid heat-polymerized which is a hybrid acrylic that is polymerized after $20 \mathrm{~min}$ in boiling water. The initiator combines both chemical and heat activated.

Inorganic filler particles have been used to reinforce polymers. Most of these particles are hydrophilic and have an affinity to agglomerate in a hydrophobic environment like PMMA therefore coupling agents are used to improve the fillers compatibility with organic matrices of the polymer. Tan et al. [18] and Chmielwska et al. [19] have developed separate silane treatment methods as particle surface modifiers, with 3-methacryloxypropyltrimethoxysilane (MPTS) being the most popular saline coupling agent. MPTS is bipolar molecule with hydrophilic and hydrophobic ends. It has the ability 
to bond to the inorganic filler particle through its hydrophilic end. The hydrophobic end of MPTS has alkoxysilane groups that bond to neighbouring MPTS molecules and copolymerised with acrylic monomers [20].

MPTS is absorbed into the particle surface by a hydrogen bond between the silanol group of MPTS and hydroxyl group of the particle surface. These hydrogen bonds are loose and are assumed to be converted into a covalent bond after drying at room temperature [21].

Previous attempts to improve properties of PMMA have resulted in improvement of some mechanical properties at the cost of other advantageous [22,23]. This is assumed to be due to poor compatibility and uneven distribution of the particulates within the polymer.

\section{Aim}

This study was designed to improve PMMA fracture resistance by modifying the surface of the particles and dispersing particles uniformly throughout the polymer. This experiment comprises of three stages: (I) Developing a technique to polymerise the monomer without mixing with PMMA powder to be able to disperse the particles within the whole polymer bulk; (II) modifying the surface of the filler particles to create a good bonding with resin matrix; (III) dispersion of the surface-modified particles within the monomer, preventing agglomeration (Figure 2).
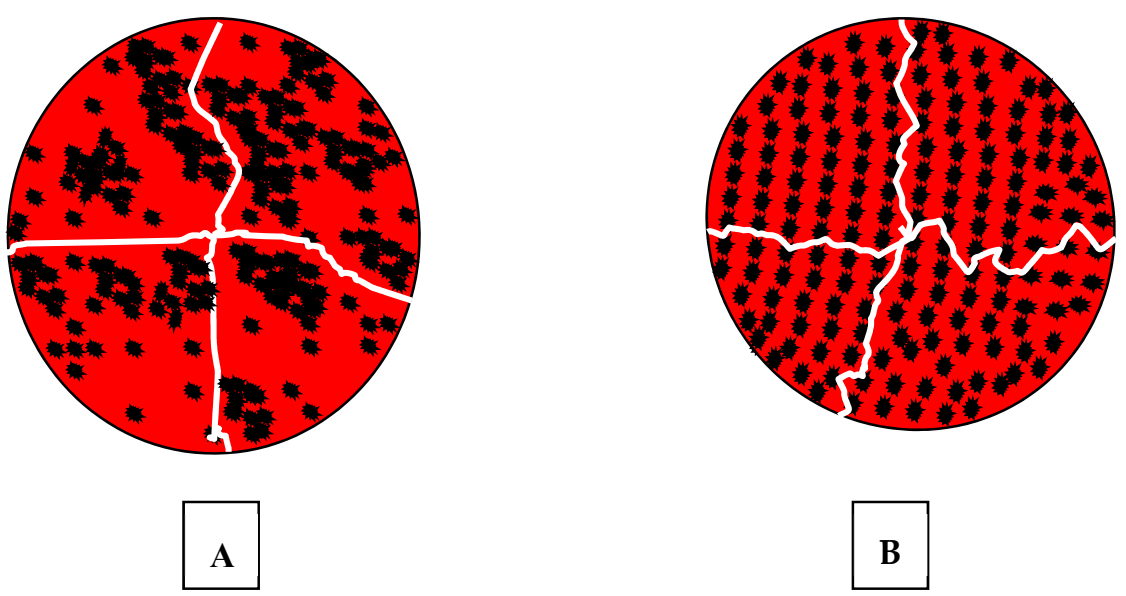

Figure 2. Schematic distribution of filler particles within the resin; (A) agglomerated, weekly bonded and randomly distributed particulates allow cracks to grow pass by them without obstruction. (B) uniformly dispersed particles, bonded to the resin matrix, divert cracks with increased fracture toughness of the material.

\section{Materials and Methods}

\subsection{Materials}

$\mathrm{TiO}_{2}$ (Titanium oxide Anhydrous, Fisher Scientific UK Ltd., Bishop MeadowRoad, Loughborough, Leicestershire, UK) particles with a particle size of around $25 \mu \mathrm{m} . \mathrm{ZrO}_{2}$ (Zirconium Dioxide, Fisher Scientific UK Ltd., Bishop Meadow Road, Loughborough, Leicestershire, UK) with particle size of $25 \mu \mathrm{m} . \mathrm{Al}_{2} \mathrm{O}_{3}$ (Aluminium oxide, Fisher Scientific UK Ltd., Bishop Meadow Road, Loughborough, Leicestershire, UK) particles with a particle size of around $25 \mu \mathrm{m}$. PMMA—silica nanocomposite, $264 \mathrm{~nm}$ (prepared with $20 \mathrm{~nm}$ aqueous silica sol and surface characterised by Department of Chemistry of Sheffield University) Closite 30B, 20A, 93A and laponite (Southern Clay Products-a synthetic layered silicate incorporating an inorganic polyphosphate peptiser). Methyl methacrylate monomer (Oracryl denture material, Bracon, Etchingham, West Sussex, UK). Benzoyl peroxide 70\% (Sigma-Aldrich Company Ltd., St. Louis, MO, USA). N,N dimethyl-p-toluidine (Sigma-Aldrich Company Ltd.) Silane-treated silica particles (Dentspy Ltd., York, PA, USA). Acrylic coated glass flakes (0.8-1.2 $\mu \mathrm{m})$ (Glass Flakes Limited, Froster st., Leeds, UK). 3-methacryloxypropyltrimethoxysilane 
(MPTS) (Onichem Specialities Co., Ltd., Dalian, China). Enigma High-Base (Davis Schottlander \& Davis LTD, Letchworth, UK).

\subsection{Methods}

\subsubsection{Stage I-Polymerisation of MMA}

The authors found no studies in which the filler particles were distributed in the polymer beads and the monomer. The filler particles are mostly incorporated in monomer part of the material, which is almost one third of the polymerised form. This means that the particles distributed within the matrix only. In this study particles were dispersed in the monomer and polymerised without adding polymer beads. Therefore, a series of innovative procedures were tried to develop a technique for polymerisation of MMA without adding PMMA powder.

One hundred and eighty, grams ( 200 cc) of monomer, MMA, was mixed with $1.8 \mathrm{~g}$ benzoyl peroxide $70 \%(1 \mathrm{w} \%)$, as a heat-cure initiator, then was poured in a plaster mould prepared in a two-part brass flask (Figure 3). Two sets of flasks were prepared and heated to $95^{\circ} \mathrm{C}$ and $60{ }^{\circ} \mathrm{C}$ for $2 \mathrm{~h}$ in a dry-heat oven. This attempt at polymerisation failed due to monomer evaporation before polymerisation could take place. The experiment was repeated with a sealed mould, which resulted in malformed, porous and shrunken polymerised specimens from high volume of contraction on the monomer during polymerisation. An alternative method was designed where $1.8 \mathrm{~g}(\sim 1 \mathrm{w} \%)$ of a chemical initiator, $\mathrm{N}, \mathrm{N}$ dimethyl-p-toluidine, was added to the mixture of $180 \mathrm{~g}$ of MMA and $1.8 \mathrm{~g}$ of benzoyl peroxide and mixed with a magnetic stirrer for $50 \mathrm{~min}$. This was poured into the mould as the mixture started to gel. The mould was stored for $24 \mathrm{~h}$ at ambient temperature for chemical curing then heated in a water bath at $95^{\circ} \mathrm{C}$ to complete the polymerization. Visual inspection of the polymerised specimen showed that this dual-curing technique eliminated the problems of shrinkage and porosity of the resin. To reduce curing time to $10 \mathrm{~min}$, the amount of benzoyl peroxide and chemical initiator were increased to $2 \mathrm{w} \%$ and $3 \mathrm{w} \%$.

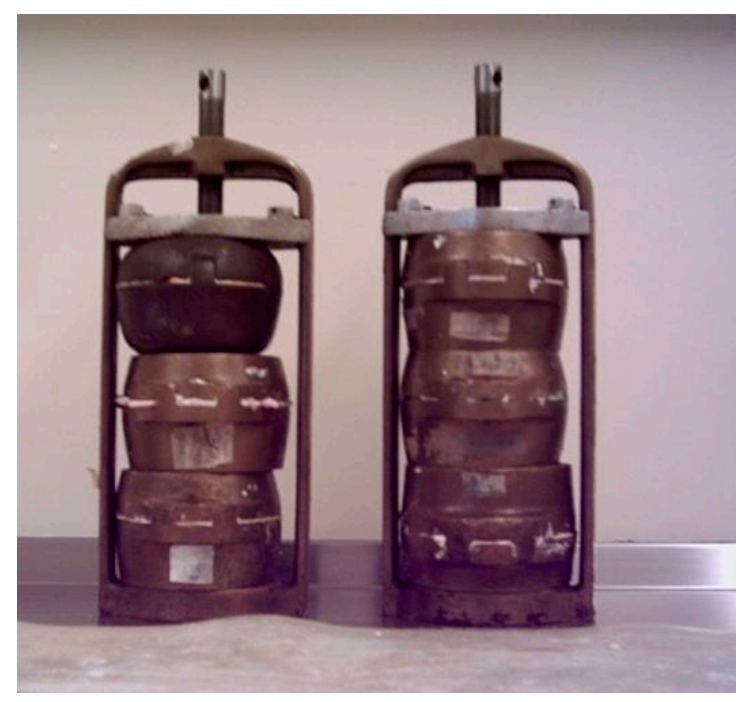

Figure 3. Conventional two-part brass flasks used in dental laboratories.

\subsubsection{Stage II—Surface Modification of Particles}

To bond the inorganic filler particles to the resin matrix, the surface of the particles was impregnated with silane coupling agents. The authors could not find a commonly agreed procedure for silanation of various types of particles in the literature; therefore, they decided to develop a procedure using methods employed in previous studies and some innovative techniques as follows. 
The control group was silane-treated silica particles dispersed using the same method of dispersion as experimental particles. Nanoclay filler particles, Closite 30B, Closite 20A, Closite 93A, and micron size filler particles, $\mathrm{TiO}_{2}, \mathrm{ZrO}_{2}$ (both particle sizes of $25 \mu \mathrm{m}$ ), $\mathrm{Al}_{2} \mathrm{O}_{3}$-PMMA (264 nm), were mixed individually with $1.8 \mathrm{~g} 2 \mathrm{~mL}$ MMA by ultrasonication at a frequency of $40 \mathrm{KHz}$ for $10 \mathrm{~min}$. These particles were then treated with the following experimental methods adapted from previous studies carried out by Albaladejo et al. [24] and Brentel et al. [25], to discover the optimal conditions.

Method I-Ethyl alcohol, 99\% solution, was used as a solvent and is $\mathrm{pH}$ altered to $4.5-5.5$ with acetic acid. A total of $0.25 \mathrm{~g}$ of MPTS, a silane coupling agent, was mixed with $5 \mathrm{~mL}$ of the solvent by magnetic stirrer, Bibby Scientific Model 8212 Magnetic Hot Plates stirrer, for 5 min at $500 \mathrm{rpm}$ and stored at room temperature for $15 \mathrm{~min}$ to be hydrolysed to silanol (hydrolyses of alkoxy groups). A total of $5 \mathrm{~g}$ of all experimental particles was dispersed in $25 \mathrm{~mL}$ of solvent individually using an ultrasonic processor, at $40 \mathrm{KHz}$, for $5 \mathrm{~min}$ and then mixed with $5 \mathrm{~mL}$ of MPTS coupling agent for a further $5 \mathrm{~min}$. The mixtures were stored at room temperature for $24 \mathrm{~h}$ to form initial hydrogen bonding between the particles and MPTS and washed three times by ethanol, $99 \%$, using a centrifuge (1500 rpm for $15 \mathrm{~min}$ ) to eliminate excess coupling agent. The excess coupling agent was assumed to encourage agglomeration of the filler particles. The precipitated particles were dried at room temperature for $24 \mathrm{~h}$ before fully drying in a furnace at $100{ }^{\circ} \mathrm{C}$ for $2 \mathrm{~h}$ to covert hydrogen bonds to covalent bonds. The silanols coordinate with metal hydroxyl groups on the inorganic surface to form an oxane bond with elimination of water.

Method II-Ethyl alcohol, 70\% solution, was used as a solvent and its $\mathrm{pH}$ altered to $4.5-5.5$ with acetic acid. A magnetic stirrer was used to mix $0.25 \mathrm{~g}$ of MPTS with $1 \mathrm{~mL}$ of solvent for $5 \mathrm{~min}$ at $500 \mathrm{rpm}$. The mixture stored at room temperature for $15 \mathrm{~min}$ to hydrolyse the silane to silanol. Five grams of closite $30 \mathrm{~B}$, closite $20 \mathrm{~A}$, laponite, $\mathrm{TiO}_{2}, \mathrm{ZrO}_{2}$ and $\mathrm{Al}_{2} \mathrm{O}_{3}$ were treated individually with $5 \%$ hydrogen peroxide for $2 \mathrm{~h}$ to encourage formation of hydroxyl groups and washed twice using $99 \%$ ethyl alcohol using a centrifuge at $2000 \mathrm{rpm}$ for $10 \mathrm{~min}$. These particles were then dispersed in the ethyl alcohol for $30 \mathrm{~min}$ by ultrasonication, at $40 \mathrm{KHz}$, then mixed with of $1 \mathrm{~mL} 5 \mathrm{w} \%$ silane coupling agent solution and stirred for one hour. The silane coupling agent solution was produced by mixing $0.25 \mathrm{~g}$ of the coupling agent and $1 \mathrm{~mL}$ ethyl alcohol 70\%. These mixtures were stored at room temperature for $24 \mathrm{~h}$ to form the initial hydrogen bonds. All mixtures were washed with ethyl $99 \%$, alcohol using a centrifuge at $2000 \mathrm{rpm}$ twice for $10 \mathrm{~min}$. The precipitated particles were dried at room temperature for $24 \mathrm{~h}$ and then placed into a furnace at $100{ }^{\circ} \mathrm{C}$ for $2 \mathrm{~h}$.

Method III-Following methods I and II, $\mathrm{Al}_{2} \mathrm{O}_{3}$ showed poor results; therefore, an alternative method was used to treat $\mathrm{Al}_{2} \mathrm{O}_{3}$ alongside $\mathrm{TiO}_{2}, \mathrm{ZrO}_{2}$ to provide a comparison from similar micron-size particles. The solvent in this case was 70\% Ethyl alcohol with $\mathrm{pH}$ adjusted to $4.5-5.5$ by acetic acid. MPTS as silane coupling agent was added to the solvent with ratio of $0.25 \mathrm{mg} / \mathrm{mL}$ and stirred with a magnetic stirrer for $5 \mathrm{~min}$. The mixture was then stored at room temperature for $15 \mathrm{~min}$ in order to hydrolyse silane to silanol. Five grams of $\mathrm{TiO}_{2}, \mathrm{ZrO}_{2}$ and $\mathrm{Al}_{2} \mathrm{O}_{3}$ were individually treated with $5 \%$ hydrogen peroxide for $2 \mathrm{~h}$ and washed twice with distilled water using a centrifuge at $2000 \mathrm{rpm}$ for $10 \mathrm{~min}$. The particles were then dispersed in $95 \%$ ethyl alcohol for $30 \mathrm{~min}$ by ultrasonication, at $40 \mathrm{KHz}$, and mixed with $1 \mathrm{~mL}$ of $5 \mathrm{w} \%$ silane coupling agent solution. This produced $0.25 \mathrm{~g}$ of MPTS and $1 \mathrm{~mL}$ of $98 \%$ ethyl alcohol. This was stirred for an hour and then stored at room temperature for $24 \mathrm{~h}$ to allow the particles to become wetted by the coupling agent. The mixtures were centrifuged at $2000 \mathrm{rpm}$ for $10 \mathrm{~min}$, precipitated particles were dried at room temperature for $24 \mathrm{~h}$, then placed into a furnace at $100{ }^{\circ} \mathrm{C}$ for $2 \mathrm{~h}$.

In all methods, a qualitative tube test (Figure 4) was used to assess the compatibilities of the particles before and after coupling treatment [26]. The surface-modified particles were mixed with monomer and added to a test tube, which was half filled with water. Well coated particles remained suspended in monomer whereas poorly treated particles settled in the water. All treated particles were compared to untreated particles after being stored for 1 and $24 \mathrm{~h}$. The control group was commercial silane-coated silica glass particles. 


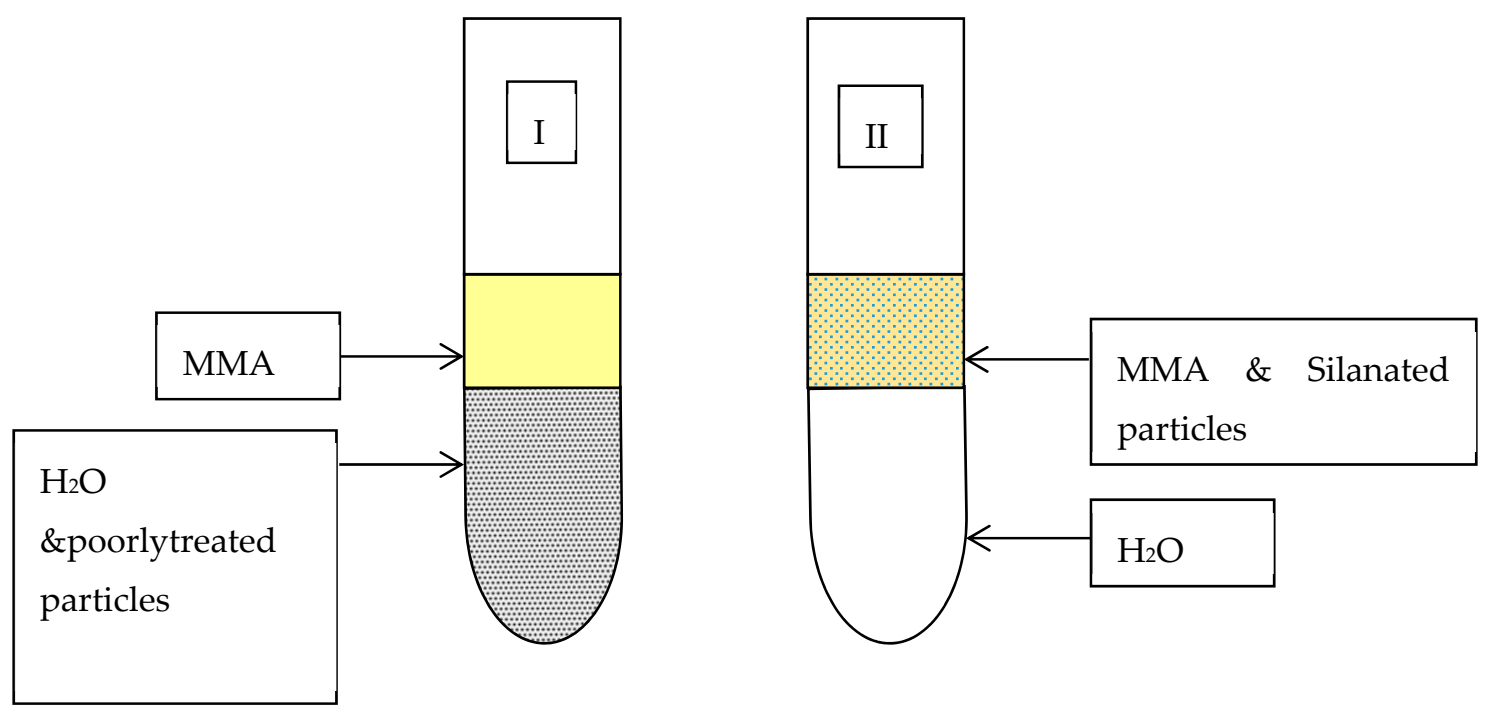

Figure 4. Qualitative method to assess the compatibility of silanated particles with MMA.

\subsubsection{Stage III—Dispersion of Filler Particles within the Resin}

To achieve uniform dispersion, particles were added into the MMA using an ultrasonic processor for $20 \mathrm{~min}$, at $40 \mathrm{KHz}$, to break down the agglomeration. As an initiator, $2 \mathrm{w} \%$ of $70 \%$ Benzoyl peroxide along with $3 \mathrm{w} \% \mathrm{~N}, \mathrm{~N}$-Dimethylptoluidine, as a chemical activator, were added to the mixture and stirred for $10 \mathrm{~min}$. When the mixture started to form into a gel, it was transferred into the mould, packed and stored at room temperature for $10 \mathrm{~min}$. The chemically curing resin was transferred into a water bath and cured at $95{ }^{\circ} \mathrm{C}$ for $2 \mathrm{~h}$ to complete the polymerisation. The moulds were either discs of $12 \mathrm{~mm}$ diameter and $2 \mathrm{~mm}$ thickness for the BFS test or bar-shaped $4 \times 10 \times 80 \mathrm{~mm} / 4 \times 4 \times 50 \mathrm{~mm}$ for Charpy impact and single notch three-point bend fracture toughness tests, respectively. Single-edge notched specimens were notched in the middle using a diamond wheel $(5 \times 0.015 \times 1 / 2$ inch $)$ to a depth of $2 \mathrm{~mm}$. The ratio of notch depth/specimen width was kept in the range 0.45 to 0.55 . Plain MMA was processed under the same condition as a control. After processing, the flasks were left to cool to room temperature, and specimens were removed with excess resin "flash" trimmed using a hand piece and a tungsten carbide bur. The specimens were further sandpapered with $600 \mu \mathrm{m}$ silicon carbide to achieve completely flat surface and uniform thickness. The finished specimens were stored at $37^{\circ} \mathrm{C}$ for $48 \pm 2 \mathrm{~h}$ in tap water.

\subsection{Control Materials}

A high-impact resin, Enigma High-Base, was prepared according to manufacturer's recommendations of $20 \mathrm{mg}$ powder and $10 \mathrm{~mL}$ monomer to compare the improvements in mechanical properties of the resin. This was cured in a water bath at $95^{\circ} \mathrm{C}$ for $2 \mathrm{~h}$ to form discs and bars for the BFS $(N=20)$, the impact strength $(\mathrm{N}=10)$ and the fracture toughness $(\mathrm{N}=10)$ tests. In addition, $1 \mathrm{w} \%$ of acrylic-coated glass flakes were mixed with Enigma high-base monomer by ultra-sonication for $10 \mathrm{~min}$, at $40 \mathrm{KHz}$, and then mixed with the powder, packed and processed under the same conditions. A commercial plain acrylic denture base, Oracryl, was also prepared with a powder to monomer ratio of $2.5: 1$ and cured in a water bath at $95^{\circ} \mathrm{C}$ for $2 \mathrm{~h}$. All specimens were stored in a water bath at $37^{\circ} \mathrm{C}$ for two days before testing.

\subsection{Testing Method}

The Charpy specimens were loaded in an impact tester Model IT503 Plastic Impact Tester, Surrey, UK) with a span length of $76 \mathrm{~mm}$ (Figure 5A). The machine was calibrated before conducting the test. The impact test was carried out at room temperature, and the impact strength of the specimen was 
calculated automatically by the machine based on the energy absorption and the specimen geometry. The fracture toughness and BFS tests were performed using the tensile-testing machine at the cross speed of 0.5 and $1 \mathrm{~mm} / \mathrm{min}$, respectively. The fracture toughness specimens were loaded in the machine with a span length of $38 \mathrm{~mm}$ and centred notch using manufacturer jig (Figure 5B).

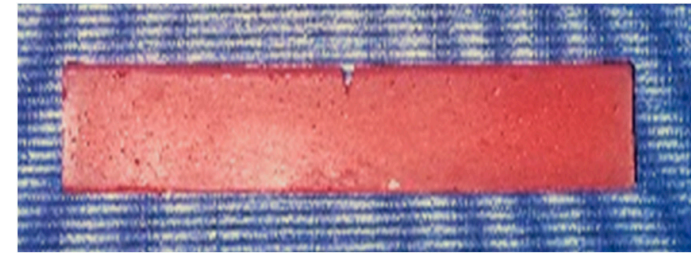

(A)
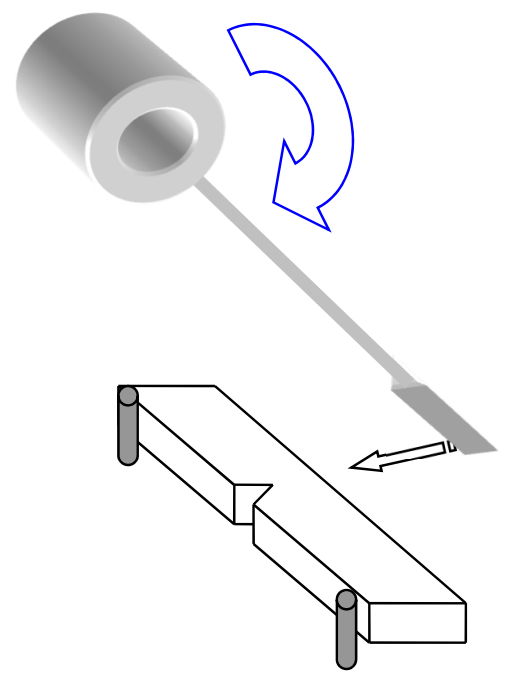

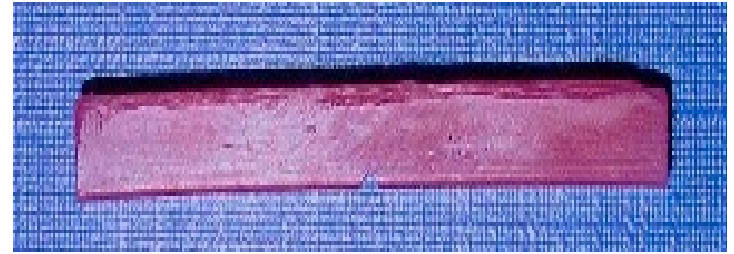

(B)

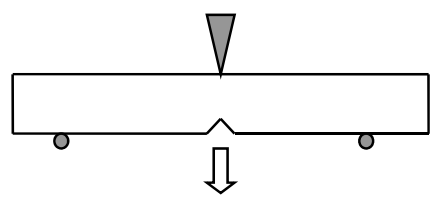

Figure 5. (A) Charpy impact test and specimen, (B) single-edge notch for fracture toughness test and specimen.

The following equation (Equation (1)) was used to calculate the fracture toughness of the specimens. Equation (1): [27] where $P=$ Peak Load, $S=$ Span, $B=$ Specimen Thickness, $W=$ Specimen Width and $a=$ Crack Length.

$$
\begin{gathered}
K I c=\left[(P \times S) /\left(B \times W^{1.5}\right)\right] \cdot f(\alpha / w) \\
f(\alpha / w)=3(\alpha / w)^{0.5}\left[1.99-(\alpha / w)(1-\alpha / w)\left(2.15-3.93 \alpha / w+2.7 \alpha^{2} / w^{2}\right)\right] \div 2(1+2 \alpha / w)(1-\alpha / w)^{1.5}
\end{gathered}
$$

A Lloyd 2000R universal testing machine, was used to measure BFS of the discs. The discs were centrally placed onto an " $\mathrm{O}$ " ring, and a ball tip instrument was used to apply load on the central point of the discs at a crosshead speed of $1 \mathrm{~mm} / \mathrm{min}$. The BFS of the specimens was calculated using the following equation (Equation (2)) in an Excel data file.

Equation (2): [28] where $\sigma_{\max }=$ maximum biaxial flexural strength, $P=$ the load to fracture, $\alpha=$ the radius of the knife-edge support ( $\mathrm{O}$ ring) and $h=$ specimen thickness

$$
\sigma_{\max }=\frac{p}{h^{2}}\left[0.606 \log _{e}\left(\frac{\mathfrak{a}}{w}\right)+1.13\right]
$$

The electron microscopic study was carried out on the fractured surfaces of plain resin, silanated silica-resin $(2 \mathrm{w} \%)$, silanated $\mathrm{TiO}_{2}-$ resin $(1 \mathrm{w} \%)$ and silanated nanoclays-resin composites. The specimens were mounted on $12.5 \mathrm{~mm}$ diameter stubs and attached with sticky tabs and then coated in an Edwards S150B sputter coater with approximately $25 \mathrm{~nm}$ of gold. The specimens were then examined in a Philips XL-20 Scanning Electron Microscope at an accelerating voltage of $20 \mathrm{Kv}$. 


\subsection{Statistical Analysis}

One-way ANOVA analysis and Turkey's comparison tests were carried out to determine significance using MINITAB $(p<0.05)$.

\section{Results}

\subsection{Surface Modification of Particles}

After $1 \mathrm{~h}$ untreated $\mathrm{TiO}_{2}$ and $\mathrm{Al}_{2} \mathrm{O}_{3}$ were completely deposited in the water whereas $\mathrm{ZrO}_{2}$ partially did. Nanoclays, closite $20 \mathrm{~A}$ and $30 \mathrm{~B}$ were mostly suspended in the monomer, whereas silane-treated silica (control group) and PMMA-impregnated colloidal silica particles were almost completely suspended in MMA (Figure 6). After $24 \mathrm{~h}$ most of the silane-treated silica particles precipitated, while there was no visually significant change in the other specimens (Figure 7).

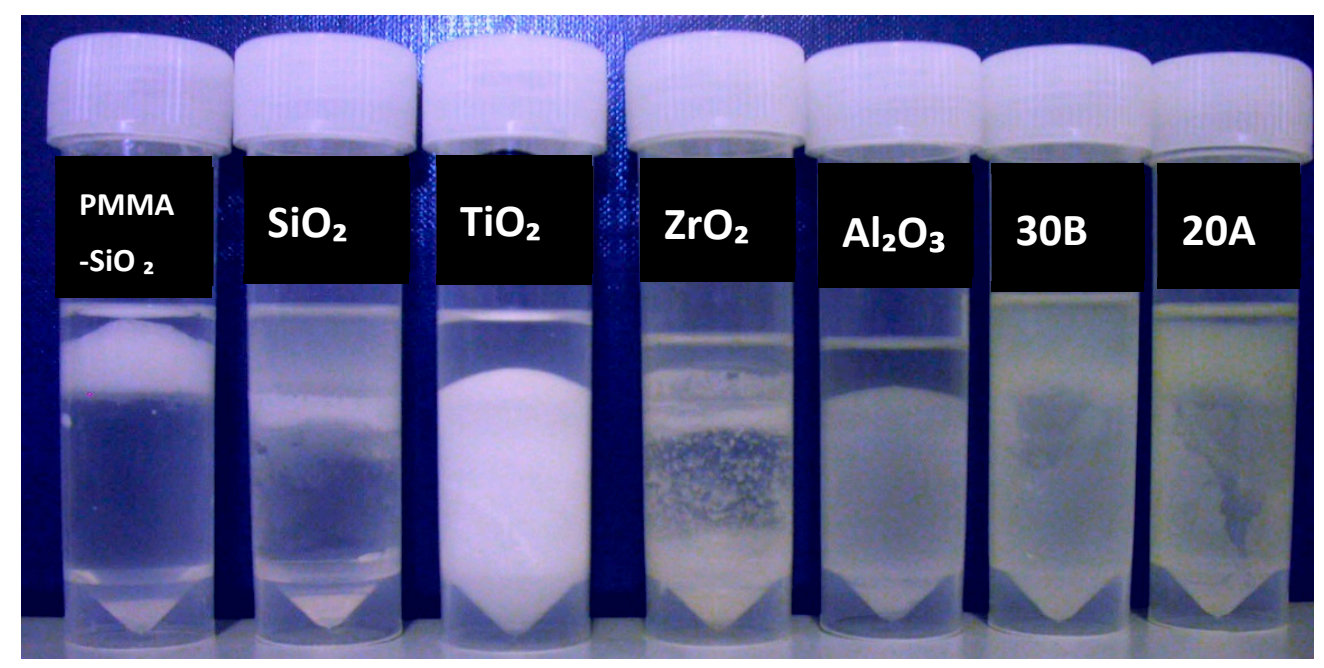

Figure 6. Particles stored for one hour after mixing with monomer, prior to silane treatment, from left to right; impregnated PMMA by silica, silane treated silica (control), untreated $\mathrm{TiO}_{2}, \mathrm{ZrO}_{2}, \mathrm{Al}_{2} \mathrm{O}_{3}$ and nanoclays $30 \mathrm{~B}$ and $20 \mathrm{~A}$.

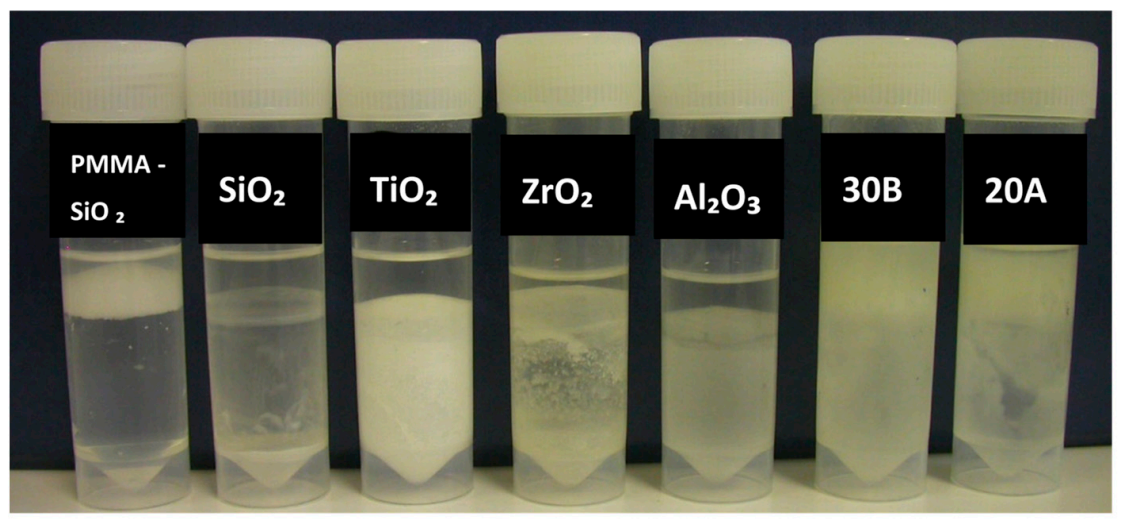

Figure 7. Particles stored for $24 \mathrm{~h}$ after mixing with monomer, prior to silane treatment, from left to right; impregnated PMMA by silica, silane treated silica, untreated $\mathrm{TiO}_{2}, \mathrm{ZrO}_{2}, \mathrm{Al}_{2} \mathrm{O}_{3}$ and nanoclays 30B and 20A.

Silane-treated particles using the method I showed that after one hour, $\mathrm{ZrO}_{2}$ and $\mathrm{TiO}_{2}$ became almost completely suspended into the monomer, but the suspension of $\mathrm{Al}_{2} \mathrm{O}_{3}$, closite $20 \mathrm{~A}$ and closite 30B had not changed (Figure 8). Further storage of the samples to 1, 3 and 7 days had no effect on the compatibility of the particles (Figure 9). 


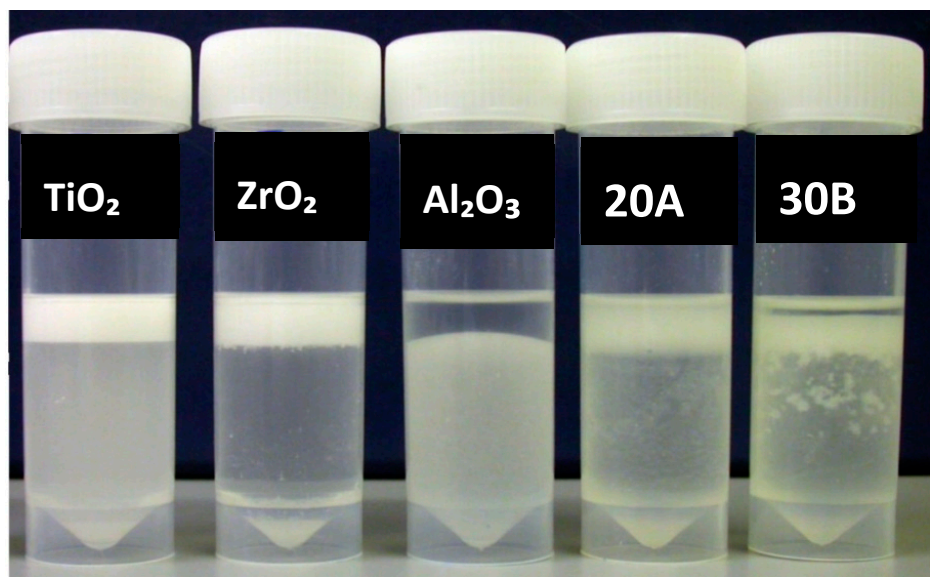

Figure 8. Particles subsequent to silane treatment, method I, mixed with monomer stored for one hour from left to right; silane treated $\mathrm{TiO}_{2}, \mathrm{ZrO}_{2}, \mathrm{Al}_{2} \mathrm{O}_{3}$ and closite $30 \mathrm{~B}$ and $20 \mathrm{~A}$.

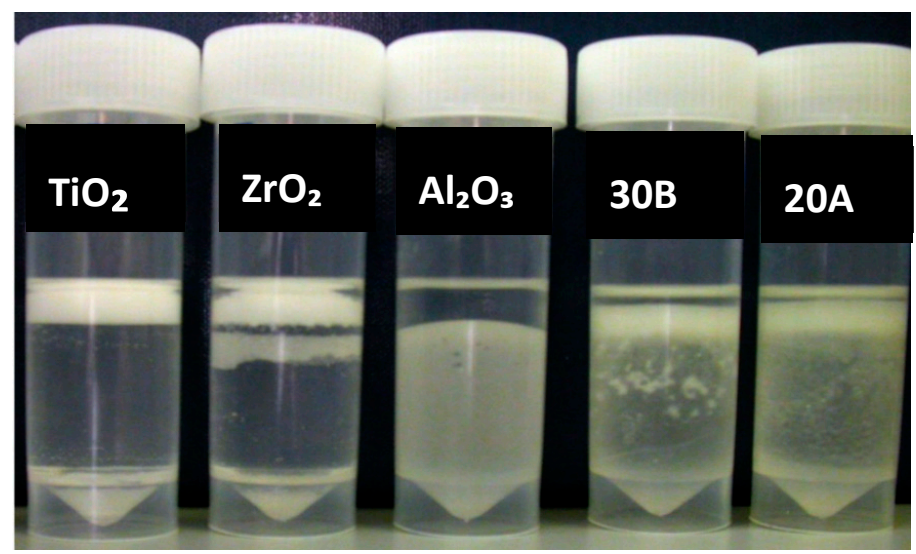

Figure 9. Particles subsequent to silane treatment, method I, mixed with monomer stored for $24 \mathrm{~h}$ from left to right; silane treated $\mathrm{TiO}_{2}, \mathrm{ZrO}_{2}, \mathrm{Al}_{2} \mathrm{O}_{3}$ and nanoclays $30 \mathrm{~B}$ and $20 \mathrm{~A}$.

The tube test of Silane-treated particles through method "II" showed that after 1-h storage, $\mathrm{TiO}_{2}$, $\mathrm{ZrO}_{2}, \mathrm{Al}_{2} \mathrm{O}_{3}$, closite $20 \mathrm{~A}$ and closite $30 \mathrm{~B}$ were partially suspended in the monomer. Silanated laponite was particularly compatible with MMA (Figure 10). Method III of silane treatment showed a medium degree of compatibility with the monomer after treatment (Figure 11).

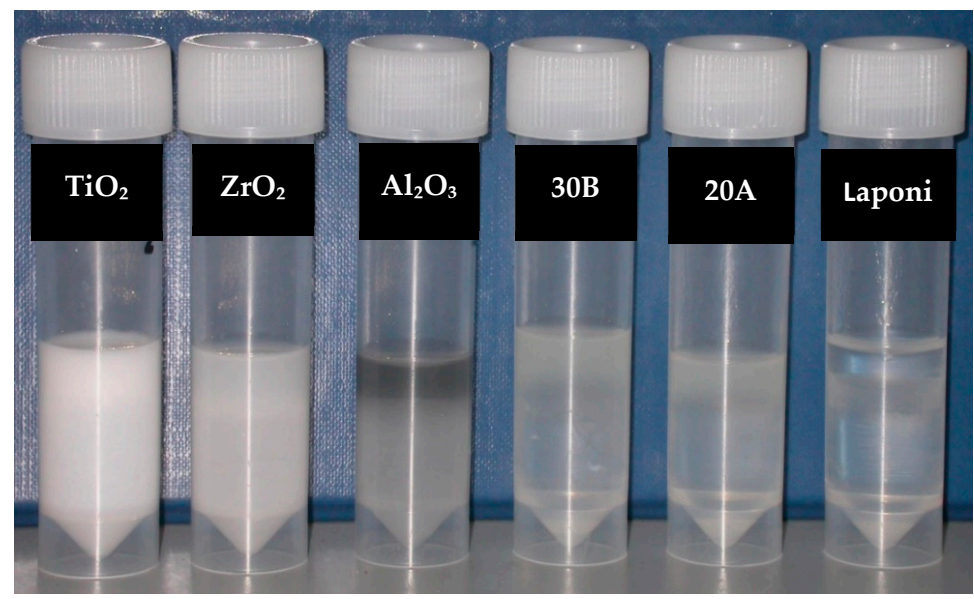

Figure 10. Particles subsequent to silane treatment, method II, mixed with monomer and stored for one hour from left to right; silane treated $\mathrm{TiO}_{2}, \mathrm{ZrO}_{2}, \mathrm{Al}_{2} \mathrm{O}_{3}$, Closite 30B, Closite 20A and laponite. 


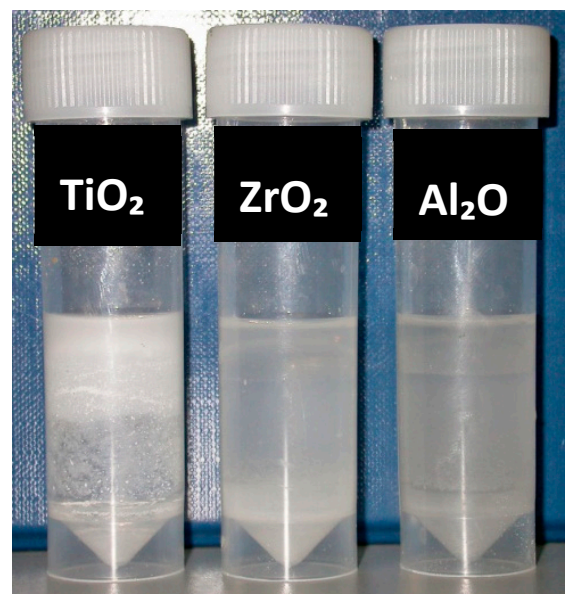

Figure 11. Particles subsequent to silane treatment, method III, mixed with monomer and stored for one hour from left to right; silane treated $\mathrm{TiO}_{2}, \mathrm{ZrO}_{2}$ and $\mathrm{Al}_{2} \mathrm{O}_{3}$.

\subsection{Biaxial Flexural Strength of Adapted Resins}

Adding $1 \mathrm{w} \%$ of acrylic coated glass flakes improved the BFS of the resin to $146 \mathrm{MPa}, \mathrm{SD} \pm 16$ $(\mathrm{N}=15)$ compared with the control group (polymerized plain monomer) which showed $121 \mathrm{MPa}, \mathrm{SD}$ \pm 12 . The difference was statistically significant $(p<0.05)$; however, increasing the particle ratio to $2 \mathrm{w} \%$ showed less improvement at $131 \mathrm{MPa}, \mathrm{SD} \pm 17$, which was not statistically significant $(p>0.05)$. Adding $5 \mathrm{w} \%$ of particles reduced the BFS of the resin to $106 \mathrm{MPa}, \mathrm{SD} \pm 11$, although the difference was not statistically significant $(p>0.05)$ (Figure 12 and Table 1). Adding PMMA-silica nanocomposite, silanated A20, B nanoclays, silanated $\mathrm{TiO}_{2}$ and $\mathrm{ZrO}_{2}$ reduced the mean BFS of the resin to $100, \mathrm{SD} \pm 11$, $103, \mathrm{SD} \pm 28,109, \mathrm{SD} \pm 31,113, \mathrm{SD} \pm 14,107, \mathrm{SD} \pm 16 \mathrm{MPa}$, respectively. However, the differences were not statistically significant $(p>0.05)$. Incorporation of silanated closite $\mathrm{A} 931 \mathrm{w} \%$ and silanated $\mathrm{Al}_{2} \mathrm{O}_{3}$ $1 \mathrm{w} \%$ reduced the mean BFS of the resin to $86, \mathrm{SD} \pm 9$ and $65, \mathrm{SD} \pm 12 \mathrm{MPa}$. The differences were statistically significant $(p<0.05)$. The mean BFS of $1 \mathrm{w} \%$ silanated silica composite was $116 \mathrm{MPa}$, SD \pm 6 . In comparison with the control group, the difference was not statistically significant $(p>0.05)$. Incorporation of 2,3 and $5 \mathrm{w} \%$ of silanated silica into the resin increased the mean BFS of the resin to $131, \mathrm{SD} \pm 17,123, \mathrm{SD} \pm 10,126, \mathrm{SD} \pm 11 \mathrm{MPa}$. The differences were not statistically significant compared to the control group $(p>0.05)$.

Table 1. Comparison of biaxial flexural strength of filler added resin and plain resin, MMA. * Statistically significant compared to the control group.

\begin{tabular}{|c|c|c|}
\hline PMMA Composite & BFS (MPa) & SD \\
\hline Control (cured MMA) & 121 & 12 \\
\hline ac GF, $1 \%$ & 146 * & 16 \\
\hline ac GF, $2 \%$ & 131 & 17 \\
\hline ac GF, 3\% & 106 & 11 \\
\hline PMMA-Silica, 1\% & 100 & 11 \\
\hline Closite A20, 1\% & 103 & 28 \\
\hline Closite B, $1 \%$ & 109 & 31 \\
\hline A93, $1 \%$ & $86 *$ & 9 \\
\hline $\mathrm{Al}_{2} \mathrm{O}_{3}, 1 \%$ & $65 *$ & 12 \\
\hline $\mathrm{TiO}_{2}, 1 \%$ & 113 & 14 \\
\hline Silica, $1 \%$ & 116 & 7 \\
\hline Silica, $2 \%$ & 131 & 17 \\
\hline Silica, 3\% & 123 & 10 \\
\hline Silica, $5 \%$ & 126 & 11 \\
\hline $\mathrm{ZrO}_{2}, 10 \%$ & 107 & 16 \\
\hline
\end{tabular}




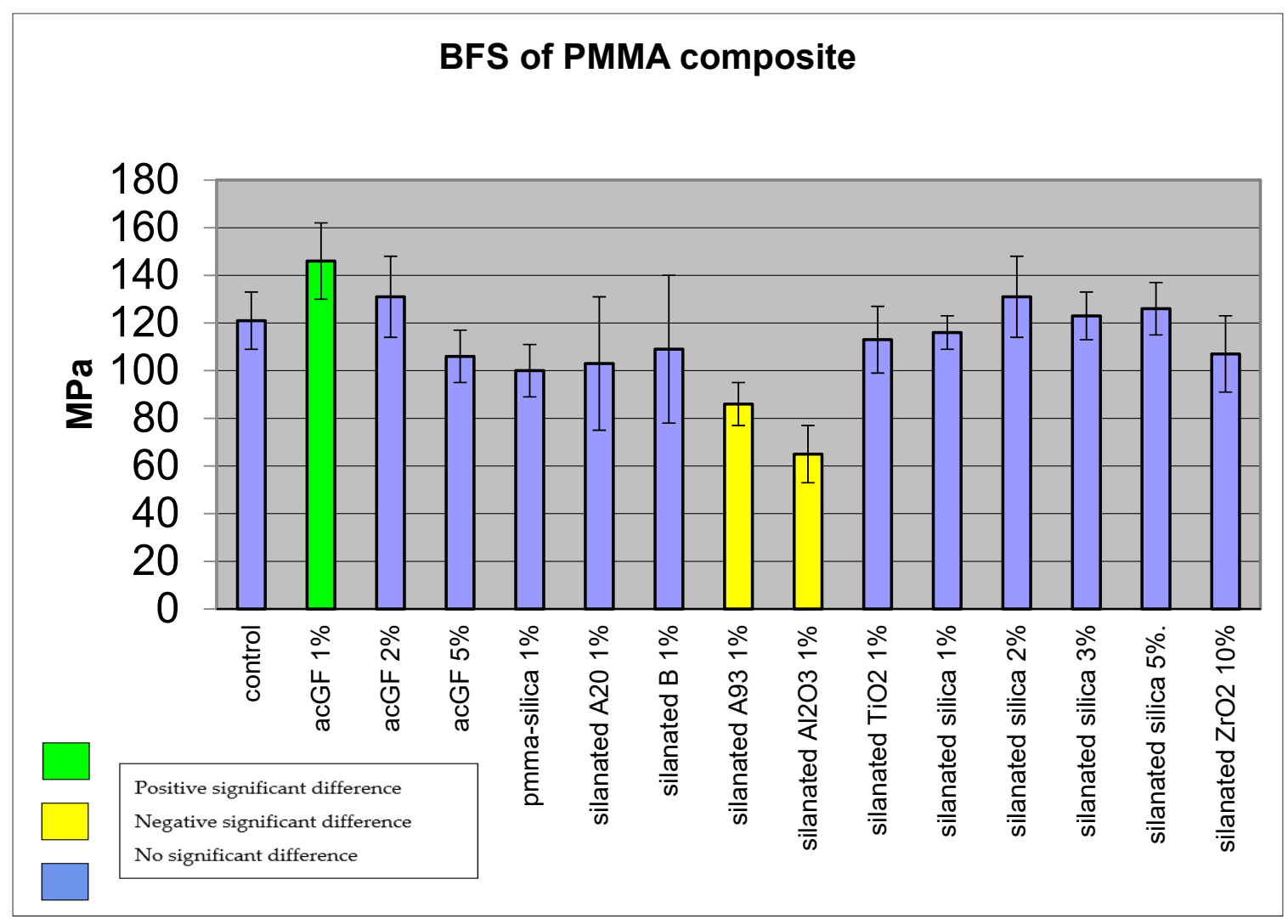

Figure 12. Comparison of biaxial flexural strength of filler added resin and plain resin.

\subsection{Impact Strength of Resins}

Incorporation of 1, 2 and $3 \mathrm{w} \%$ acrylic coated glass flakes into the resin did not improve the mean impact strength compared with the control group $(\mathrm{N}=10)$. The differences were not statistically significant in any of these ratios $(p<0.05)$ (Figure 13 and Table 2).

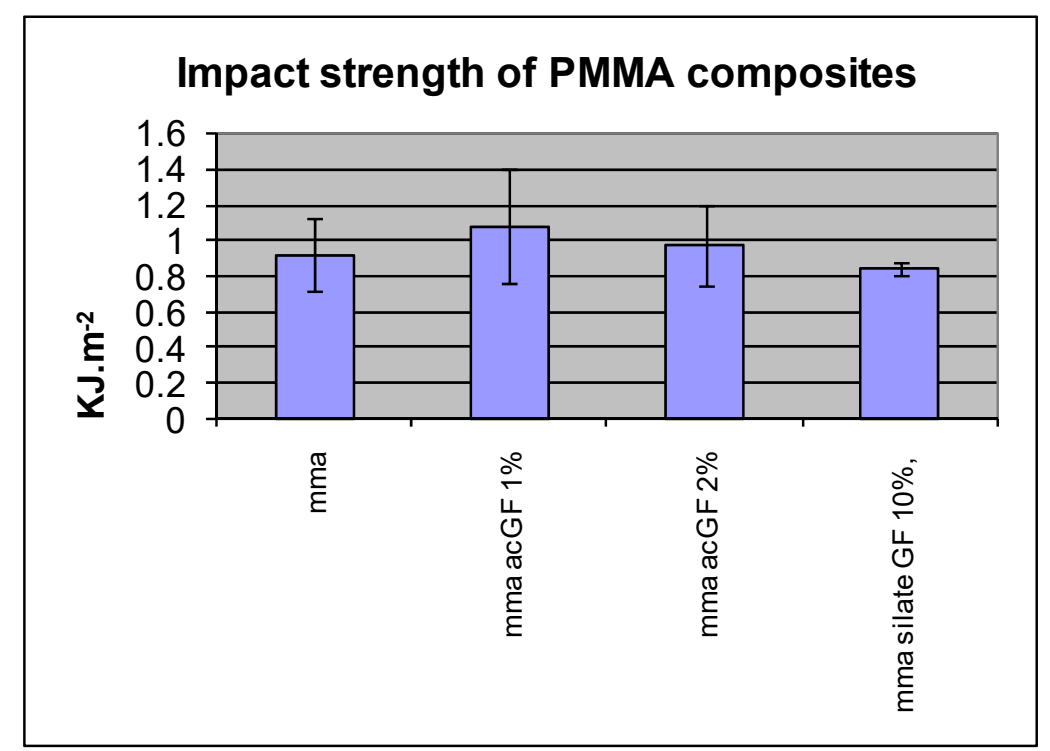

Figure 13. Effect of adding filler particles on impact strength of resins. 
Table 2. Effect of adding filler particles on impact strength of resins.

\begin{tabular}{ccc}
\hline PMMA Composite & IS KJ· $\mathbf{m}^{-\mathbf{2}}$ & SD \\
\hline Control (cured MMA) & 0.92 & 0.2 \\
ac GF, 1\% & 1.08 & 0.32 \\
ac GF, 2\% & 0.97 & 0.23 \\
ac GF, 3\% & 0.84 & 0.03 \\
\hline
\end{tabular}

\subsection{Fracture Toughness of the Adapted Resins}

Adding $1 \mathrm{w} \%$ of acrylic coated glass flakes to the resin did not improve the mean fracture toughness in comparison with the control group $(\mathrm{N}=10)$. The difference was not statistically significant $(p<0.05)$ (Figure 14 and Table 3).

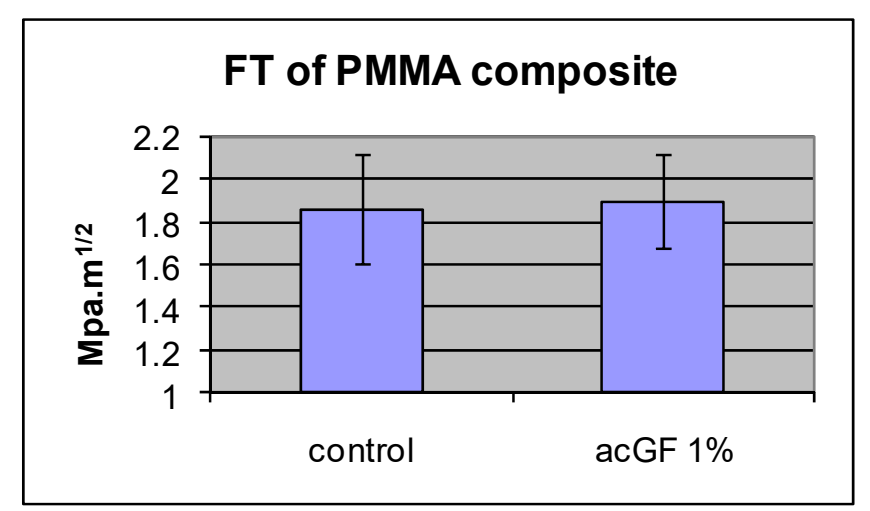

Figure 14. Effect of adding filler particles on fracture toughness of the resin.

Table 3. Effect of adding filler particles on fracture toughness of the resin.

\begin{tabular}{ccc}
\hline PMMA Composite & FT MPa $^{\mathbf{1 / 2}}$ & SD \\
\hline Control (cured MMA) & 1.86 & 0.25 \\
ac GF, 1\% & 1.9 & 0.22 \\
\hline
\end{tabular}

To study the pattern and surface specification of the fractured surface, a Scanning Electron Microscope, SEM, was used. In SEM images, the rougher fracture surface of the silica composite indicates its higher energy absorption to fracture compared with the plain resin, and the particles seem to be dispersed uniformly. The scanning showed that silane treated $\mathrm{TiO}_{2}$ and nanoclay particles were still agglomerated in the resin, and the crack went through the clusters as weak spots (Figure 15).

\subsection{High-Impact Resin Results}

The mean BFS of the high-impact resin and glass flake added $(1 \mathrm{w} \%)$ high-impact resin were $153 \mathrm{MPa}, \mathrm{SD} \pm 16$ and $152 \mathrm{MPa}, \mathrm{SD} \pm 13$, respectively $(\mathrm{N}=20)$. There was no statistically significant difference between them. The mean BFS of high-impact resin with or without the particles was not different than that of plain denture base resin $170 \mathrm{MPa}, \mathrm{SD} \pm 40$. The difference was not statistically significant $(p<0.05)$ (Figure 16 and Table 4 ). 


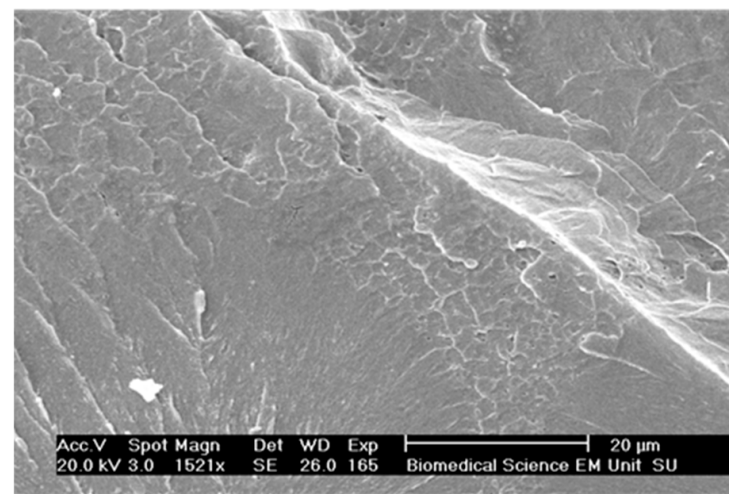

(A)

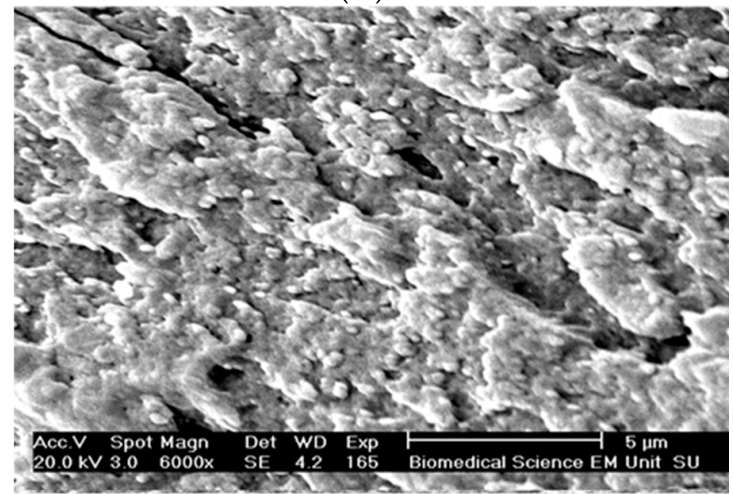

(C)

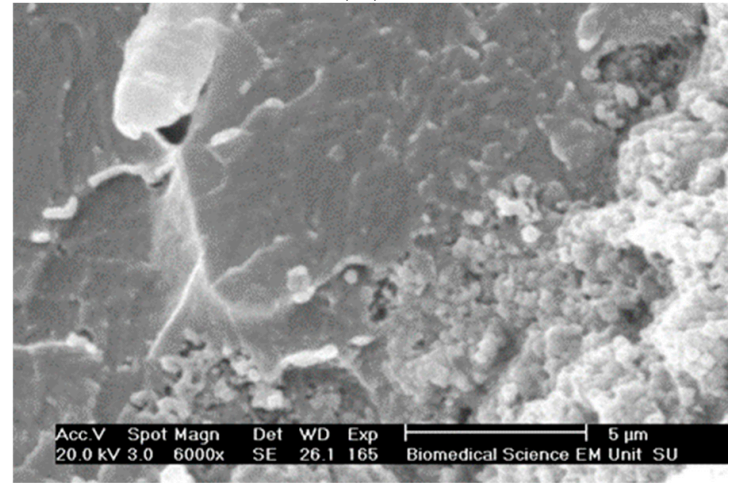

(E)

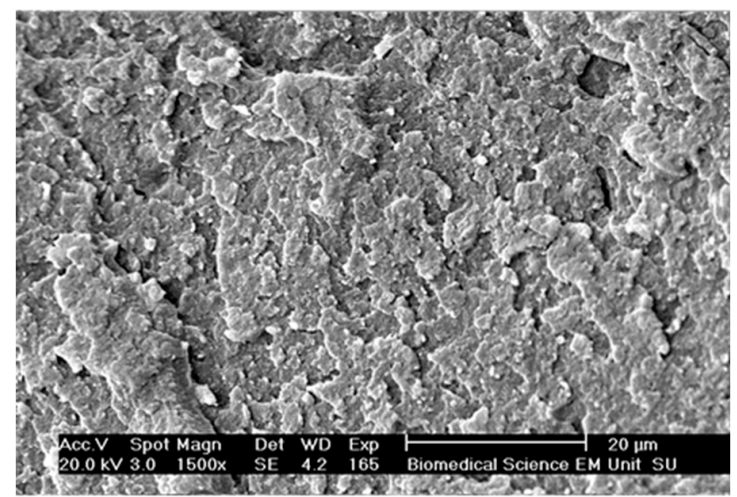

(B)

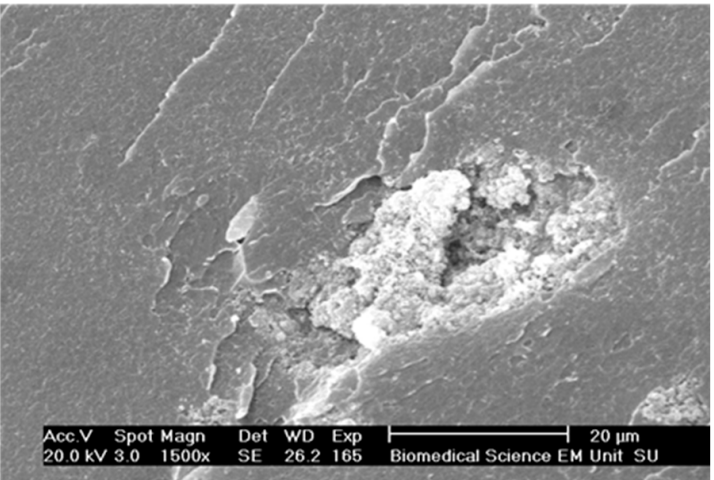

(D)

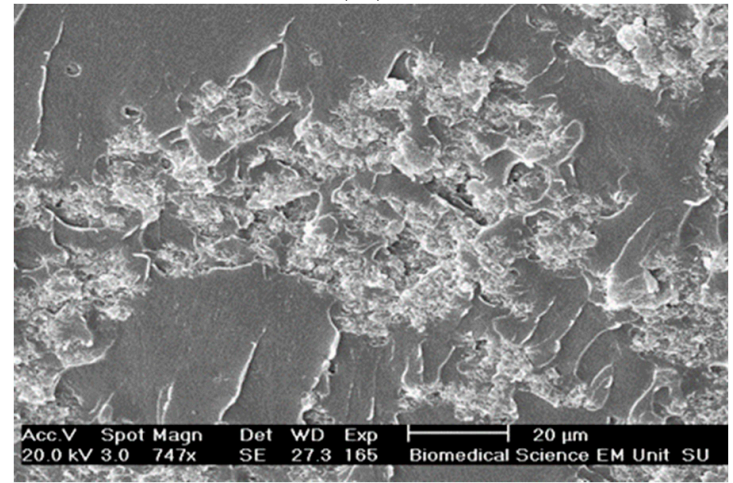

(F)

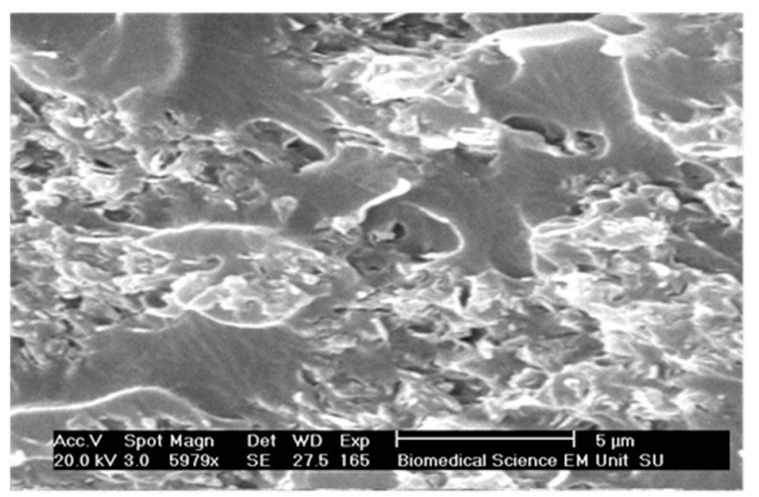

(G)

Figure 15. SEM images of fractured surfaces of the resins. (A) Plain resin. (B) Silanated silica-resin $(2 \mathrm{w} \%)$. (C) Silanated silica-resin $(2 \mathrm{w} \%)$. (D) Silanated $\mathrm{TiO}_{2}$-resin $(1 \mathrm{w} \%)$. (E) Silanated $\mathrm{TiO}_{2}$-resin $(1 \mathrm{w} \%)$. (F) Silanated nanoclay-resin composites. (G) Silanated nanoclay-resin composites. 


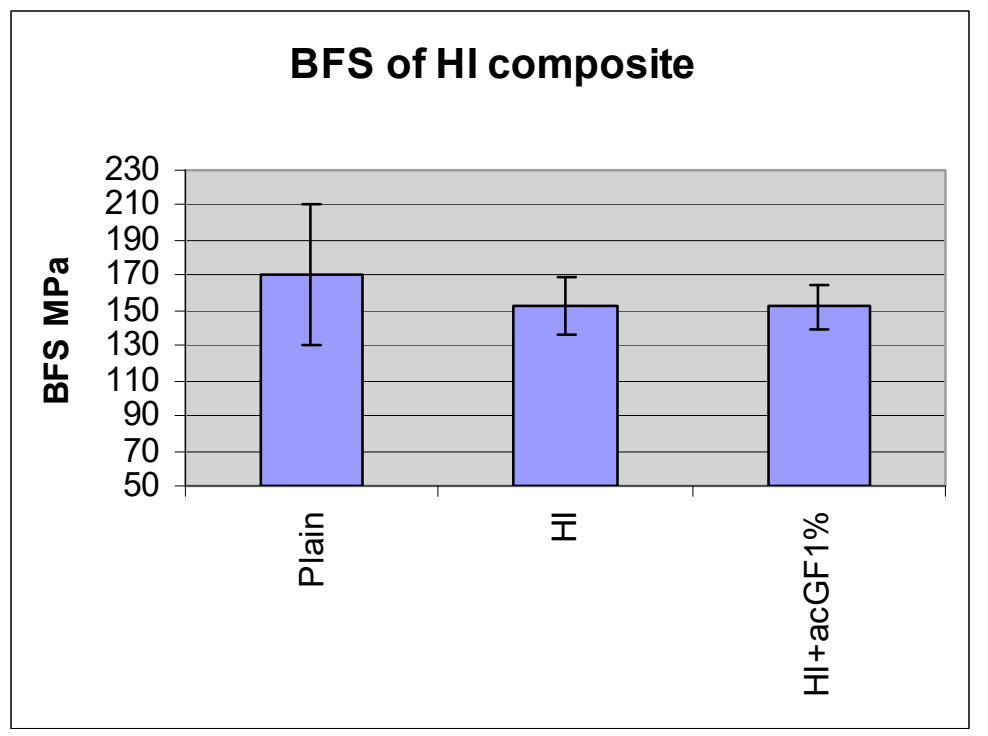

Figure 16. BFS of high-impact resin with and without added glass flakes, compared to plain denture resin.

Table 4. BFS of high-impact resin with and without added glass flakes, compared to plain denture resin.

\begin{tabular}{cccc}
\hline & Plain & HI & HI+acGF1\% \\
\hline BFS MPa & 170 & 153 & 152 \\
SD & 40 & 16 & 13 \\
\hline
\end{tabular}

\subsection{Impact Strength Results}

The mean impact strength of plain and high-impact denture base resins was $1.48, \mathrm{SD} \pm 0.06$ and $1.58, \mathrm{SD} \pm 0.16 \mathrm{KJ} \cdot \mathrm{m}^{-2}$, respectively $(\mathrm{N}=9)$. The difference between them was not statistically significant $(p<0.05)$. The incorporation of $1 \mathrm{w} \%$ acrylic coated glass flakes into the high-impact resin did not improve its mean impact strength. The difference between this composite and those of the two denture base resins was not statistically significant $(p<0.05)$ (Figure 17 and Table 5).

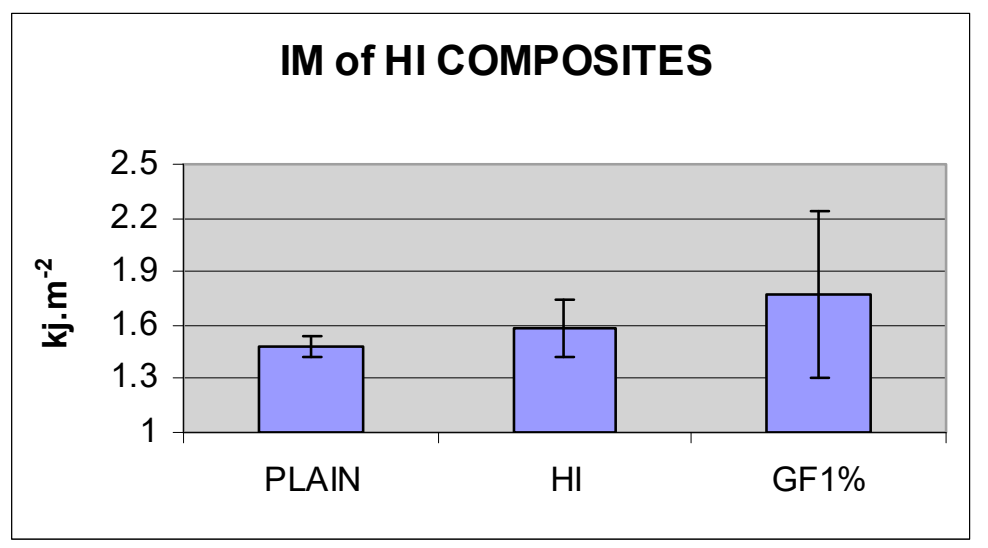

Figure 17. Impact strength of plain acrylic denture base resin, high-impact denture base resin and its composite with acrylic coated glass flakes. 
Table 5. Impact strength of plain acrylic denture base resin, high-impact denture base resin and its composite with acrylic coated glass flakes.

\begin{tabular}{cccc}
\hline & PLAIN & HI & HI+GF1\% \\
\hline${\mathrm{IM} \mathrm{KJ} \cdot \mathrm{m}^{-2}}^{\mathrm{SD}}$ & 1.48 & 1.58 & 1.77 \\
& 0.06 & 0.16 & 0.47 \\
\hline
\end{tabular}

\subsection{Fracture Toughness Results}

The fracture toughness of plain and high-impact denture base resin was $2.24, \mathrm{SD} \pm 0.38$ and 3.02, $\mathrm{SD} \pm 0.25 \mathrm{MPa} \cdot \mathrm{m}^{1 / 2}$, respectively. The difference between them was statistically significant $(p>0.05)$. Adding $1 \mathrm{w} \%$ of acrylic coated glass flakes to high-impact resin did improve its fracture toughness to $3.43 \mathrm{MPa} \cdot \mathrm{m}^{1 / 2}, \mathrm{SD} \pm 0.78$. The difference between this composite and the high-impact resin was not statistically significant $(\mathrm{N}=9)(p<0.05)$ (Figure 18 and Table 6).

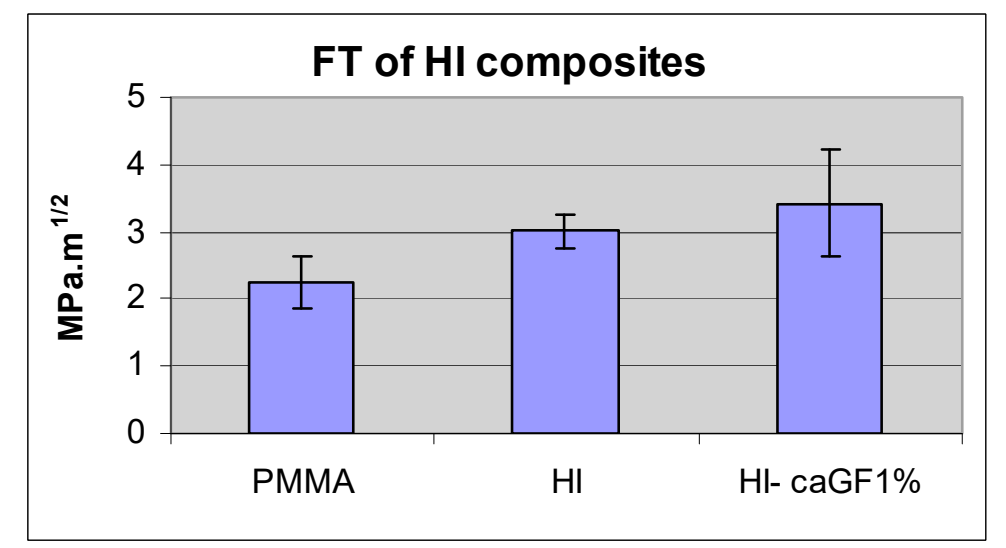

Figure 18. Fracture toughness of the plain acrylic denture base resin, high-impact denture base resin and its composite with acrylic coated class flakes.

Table 6. Fracture toughness of the plain acrylic denture base resin, high-impact denture base resin and its composite with acrylic coated class flakes. ${ }^{*}$ Statistically significant compared to the plain resin.

\begin{tabular}{cccc}
\hline & PMMA & HI & HI+GF1\% \\
\hline FT MPa $\cdot \mathrm{m}^{1 / 2}$ & 2.24 & $3.02 *$ & 3.43 \\
SD & 0.38 & 0.25 & 0.78 \\
\hline
\end{tabular}

\section{Discussion}

\subsection{Surface Treatment}

The tube test of the particles revealed that the storage time of untreated inorganic micro and nanoparticles within the monomer did not affect their compatibility. The commercial silane-treated silica glass particles retained their compatibility with monomer for one hour; however, in the longer period, $24 \mathrm{~h}$, they lost this property, which may be due to hydrolysis of oxane bond (Si-O-Si) between the coupling agent and the particle surface in an aqueous environment. The silane treatment of $\mathrm{ZrO}_{2}$ and $\mathrm{TiO}_{2}$ particles improved their compatibility with MMA, which was stable at least for one week; however, silanation of nanoclays had no or limited effect on their compatibility with the hydrophobic environment. The results showed that compatibility of $\mathrm{Al}_{2} \mathrm{O}_{3}, \mathrm{ZrO}_{2}$ and $\mathrm{TiO}_{2}$ could be altered by implementing different silanation techniques. This finding is consistent with results of previous studies [20]. Hydrogen peroxide pre-treatment prior to coupling agent treatment in Methods II and III was employed to increase the number of the hydroxyl group on the particle surface and seems to be effective in the case of $\mathrm{Al}_{2} \mathrm{O}_{3}$. However, this technique reduced the compatibility of $\mathrm{ZrO}_{2}$ and $\mathrm{TiO}_{2}$ and 
had no effect on nanoclays in comparison with the results of method I. This difference is assumed to be created by the different physical and chemical characteristics of the particles. The test tube results also showed that rinsing the $\mathrm{TiO}_{2}$ and $\mathrm{Al}_{2} \mathrm{O}_{3}$ particles after coupling agent treatment in method II decreased their compatibility with the resin in comparison with unwashed particles in method III. This is consistent with the result of a study conducted by Liu et al. [21] in which loosely adsorbed coupling agent was washed out due to lose bonding to the particle surface. Therefore, the silane treatment technique should be optimized for each individual type of the particles.

\subsection{Mechanical Properties of Filled Conventional Acrylic Resin}

The incorporation of $1 \mathrm{w} \%$ acrylic coated glass flakes improved the BFS of the resin, which may be because of their uniform dispersion and physical or chemical bonding to the resin matrix due to reducing inherent flaw size. This enables efficient stress transfer between the filler particles and the resin matrix. However, increasing the ratio of the particles to $5 \%$ decreased the strength compared with that for $1 \mathrm{w} \%$. This result is in accordance with the finding of other studies by Adabo et al. [29] and Mortazavi et al. [30]. A possible explanation for this is the fact that the more particles are introduced to the resin, the more likelihood of agglomeration will occur within the resin. The clustered particles can potentially act as a void in the resin and therefore reduce the overall strength of the resin. Despite showing good compatibility with monomer, $\mathrm{TiO}_{2}$ and $\mathrm{ZrO}_{2}$ had no significant effect on the BFS of the resin possibly because of agglomeration of the particle prior to silane treatment that resulted in silane-coated clusters. These clusters, although suspended in the monomer, may act like a void in the cured resin (Figure 19). This is further supported by SEM images taken from the fracture surface (Figure 15D,E). In addition, the spatial orientation of the silane molecules and the creation of cross-linked multilayer coupling agent around the particles reduced the number of hydrophobic functional groups available to react with matrix monomer [20,31]. This result is consistent with the finding of a similar study in which silanated zirconium oxide nanoparticulates were incorporated into the matrix of PMMA [32]. However, another study showed incorporation of $\mathrm{ZrO}_{2}$ nanoparticles improved the bending strength and fracture toughness of high-impact denture materials at the cost of impact strength [23]. The difference is probably due to the different particle size and testing methods used in this experiment.

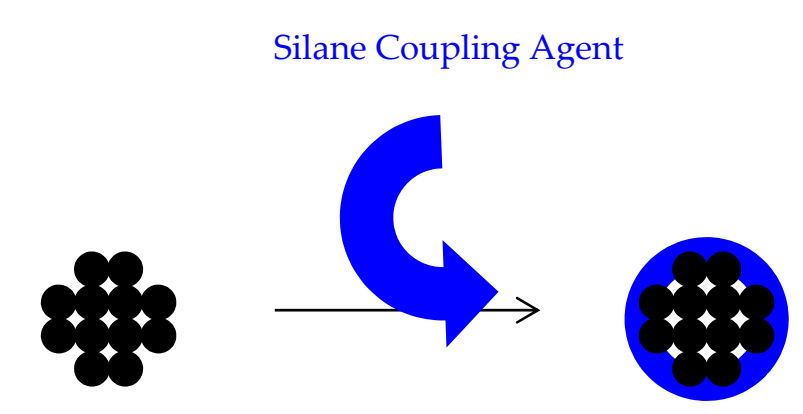

Figure 19. Speculated graphic feature of a coupling agent covered particle cluster.

The addition of PMMA-silica nanocomposite (PMMA grafted silica particles) into the resin, despite good compatibility with monomer, did not improve the strength of the resin. This may be because of a highly cross-linked PMMA shell around the silica particles, which did not react chemically with the matrix resin. Silanated Closite 20A and 30B nanoclays did not improve the BFS of the resin. This finding matches their poor compatibility with monomer and intercalated structure, which can be exfoliated when they are subjected to stress. This is consistent with the finding of Fu and Naguib [33], who revealed the agglomeration of nanoclays in acrylic resin and its negative effect on the mechanical properties of the resin. This is in contrast with findings of another research in which adding 0.25 and $0.5 \mathrm{wt} \%$ of double-modified nanoclay improved flexural strength, flexural modulus and fracture toughness of acrylic denture base [34]. This can be explained by the difference in the type 
and quality of coating and distribution of the particles in the polymer matrix as well as the testing method. The incorporation of Closite $\mathrm{A} 93$ and $\mathrm{Al}_{2} \mathrm{O}_{3}$ into the resin reduced the $\mathrm{BFS}$ of the resin. This poor compatibility of silanated $\mathrm{Al}_{2} \mathrm{O}_{3}$ explains the low strength of its composite. In addition, this result is comparable with the results of Abboud et al., [26] who showed that the incorporation of silanated alumina particles into the commercial PMMA reduced its compressive strength. Adding commercial silanated silica had no statistically significant effect on BFS of the resin. This may be due to the hydrolysis of the oxane bonds (Si-O-Si), which was already shown in the tube test. This result is consistent with the result of another study in which adding treated and untreated silica particles to the heat-cure PMMA denture base materials did not improve its transverse bend or impact strength [35]. The BFS of the composite containing $2 \mathrm{w} \%$ of the particles, showed a higher strength compared to the ratios of 3 and $5 \mathrm{w} \%$, probably due to the agglomeration of the particles. Acrylic coated glass flakes-PMMA $1 \mathrm{w} \%$ composite showed a higher BFS compared with the plain resin however, its impact strength was not significantly higher than plain resin. Similar to the BFS, the impact strength of the resin decreased when a higher ratio of the filler particles was added, which indicates a probable clustering of the particles. The fracture toughness of this composite was not different from the plain resin. Improvement of BFS, while the fracture toughness is unchanged, can be interpreted as a reduced inherent flaw size $\left(K_{I}=\uparrow \sigma \sqrt{ } \pi \downarrow \downarrow\right)$. This means that acrylic coated glass flakes are integrated with the matrix resin.

\subsection{Mechanical Properties of High-Impact Resin}

There was no significant difference between the BFS of the high-impact resin and plain acrylic resin. Yield strength of the high-impact resin is expected to be lower than that of plain acrylic resin due to rubbery particles in its structure [36] and its higher stress corrosion rate [36,37]. The acrylic coated glass flake-high-impact resin composite of $1 \mathrm{w} \%$ also showed the same BFS as the tested high-impact resin. The possible explanation for the lack of improvement in BFS of this composite is that the glass flake was introduced only into the matrix of the resin and not in the whole polymer bulk. This forms almost one-third of the polymer bulk and therefore, the weight ratio of the glass flake in the matrix was around $2 \%$ to $3 \%$, which was shown in the previous experiment to have the same BFS as the plain resin. Despite statistically insignificant differences, the high-impact resin exhibited 6\% higher impact strength compared to the plain acrylic resin, and glass-flake high-impact composite of $1 \mathrm{w} \%$ demonstrated an increase of $12 \%$ impact strength compared to the high-impact resin itself. If there is a clinically significant difference between the performance of the high-impact resin and plain acrylic resin, it can be concluded that there should be also a clinically significant difference between glass flake added Enigma high base and pure Enigma high base. Thus, a clinical trial study is suggested to investigate the clinical performance of these resins in the oral environment. As expected, the mean fracture toughness of high-impact resin was higher than the plain resin [36]. Although adding acrylic coated glass flakes into the high-impact resin improved its mean fracture toughness further, the differences still were not statistically significant. An unchanged BFS and a slightly increased mean fracture toughness of glass flake filled high-impact resin in comparison with the plain high-impact resin indicates an increase in inherent flaw size of the composite $\left(\uparrow K_{I}=\sigma \sqrt{ } \pi \uparrow \uparrow\right)$ probably due to the concentration of the particles in the matrix $(2-3 \mathrm{w} \%)$ and resulted in increased agglomeration.

It has also been shown by Cazzaniga, Ottobelli [38], that the surface roughness of the resin composites are affected by type and size of the filler particles, which in turn can affect the other mechanical properties such as bending strength and fracture toughness.

As an invitro study, the results should be interpreted within its limitations. Further assessment of surface characteristic of filler particles and their distribution in resin matrix is needed to find out the nature of interaction between different phases of composite resins. 


\section{Conclusions}

Silane coupling treatment can modify the surface of inorganic particles making them compatible with acrylic monomer. The success of treatment varies depending on the type of particles and treatment method. Surface modified particles could improve the mechanical properties of PMMA as a denture base resin, provided a uniform dispersion is achieved. Surface modified particles may improve the mechanical properties of high-impact denture base resins; however, the clinical performance of any altered and high-impacted resins will need to be studied to ensure suitability for denture practice. It can be concluded that the silane treatment regime of $\mathrm{TiO}_{2}$ particles should not comprise hydrogen peroxide pre-treatment and rinsing after the coupling agent treatment. In the case of $\mathrm{ZrO}_{2}$, hydrogen peroxide pre-treatment must be avoided. Although the chemical compatibility of $\mathrm{Al}_{2} \mathrm{O}_{3}$ particles can be improved by applying hydrogen peroxide prior to silanation, further improvement is still required. Silane coupling agent treatment had no effect on the compatibility of the nanoclays. A dual cure polymerisation technique was developed to polymerise MMA containing uniformly dispersed surface modified filler particles. The results revealed that compatibility of the surface modified particles with resin is not the only factor that may affect their performance as reinforcements; the chemical and physical structure of the particles, their dispersion before and after treatment and the chemical characteristics of their coating layer are also influential factors. Adding acrylic coated glass flakes improved the BFS and impact strength of the resin without affecting its fracture toughness, although clustering of the particles still occurs at higher particle to resin ratios. These particles also improved the impact strength of high-impact denture base resin without affecting its BFS and fracture toughness. Further analysis of surface characteristic of coated particles as well as distribution patterns of the filler particles within the resin matrix is recommended. This would help to understand the relation between the particles and their distribution on mechanical behaviour of the resin composites.

Author Contributions: T.N., designed and conducted the research, N.N. provided technical advice, L.T. helped with writing up the research and F.S. provided technical advice and helped with data analyses. All authors have read and agreed to the published version of the manuscript.

Funding: This research received no external funding.

Conflicts of Interest: The authors declare no conflict of interest.

\section{References}

1. Alla, R.; Raghavendra, K.N.; Vyas, R.; Konakanchi, A. Conventional and contemporary polymers for the fabrication of denture prosthesis: Part I-Overview, composition and properties. Int. J. Appl. Dent. Sci. 2015, $1,82-89$.

2. Jagger, D.; Harrison, A.; Jandt, K. The reinforcement of dentures. J. Oral Rehabil. 1999, 26, 185-194. [CrossRef] [PubMed]

3. John, J.; Gangadhar, S.; Shah, I. Flexural strength of heat-polymerized polymethyl methacrylate denture resin reinforced with glass, aramid, or nylon fibers. J. Prosthet. Dent. 2001, 86, 424-427. [CrossRef] [PubMed]

4. Darbar, U.; Huggett, R.; Harrison, A. Denture fracture-A survey. Br. Dent. J. 1994, 176, 342-345. [CrossRef] [PubMed]

5. Vallittu, P.; Alakuiala, P.; Lassila, V.; Lappalainen, R. In vitro fatigue fracture of an acrylic resin-based partial denture: An exploratory study. J. Prosthet. Dent. 1994, 72, 289-295. [CrossRef]

6. Vallittu, P. Comparison of the in vitro fatigue resistance of an acrylic resin removable partial denture reinforced with continuous glass fibers or metal wires. J. Prosthodont. 1996, 5, 115-121. [CrossRef] [PubMed]

7. El-Sheikh, A.M.; Al-Zahrani, S.B. Causes of Denture Fracture: A Survey. Saudi Dent. J. 2015, 18, 149-154.

8. Härle, F. Follow-up investigation of surgical correction of the atrophic alveolar ridge by visor-osteotomy. J. Maxillofac. Surg. 1979, 7, 283-293.

9. Ganzarolli, S.; De mello, J.; Shinkai, R.; Del Bel Cury, A. Internal adaptation and some physical properties of methacrylate-based denture base resins polymerized by different techniques. J. Biomed. Mater. Res. Part B Appl. Biomater. 2007, 82, 169-173. [CrossRef] 
10. Nejatian, T.; Sefat, F.; Johnson, T. Impact of Packing and Processing Technique on Mechanical Properties of Acrylic Denture Base Materials. Materials 2015, 8, 2093-2109. [CrossRef]

11. Lamb, D.; Ellis, B.; Van Noort, R. The fracture topography of acrylic dentures broken in service. Biomaterials 1985, 6, 110-112. [CrossRef]

12. Kim, S.; Watts, D. The effect of reinforcement with woven E-glass fibers on the impact strength of complete dentures fabricated with high-impact acrylic resin. J. Prosthet. Dent. 2004, 91, 274-280. [CrossRef] [PubMed]

13. Nejatian, T.; Johnson, A.; Van Noort, R. Reinforcement of denture base resin. Adv. Sci. Technol. 2006, 49, 124-129. [CrossRef]

14. Stafford, G.; Huggett, R.; MacGregor, A.; Graham, J. The use of nylon as a denture-base material. J. Dent. 1986, 14, 18-22. [CrossRef]

15. Yunus, N.; Rashid, A.; Azmi, L.; Abu-Hassan, M. Some flexural properties of a nylon denture base polymer. J. Oral Rehabil. 2005, 32, 65-71. [CrossRef] [PubMed]

16. Hedzelek, W.; Gajdus, P. Comparison of mechanical strength of palatal denture bases made from various plastic materials. Int. J. Prosthodont. 2006, 19, 193-194.

17. Acquaviva, P.A.; Cerutti, F.; Adami, G.; Gagliani, M.; Ferrari, M.; Gherlone, E.; Cerutti, A. Degree of conversion of three composite materials employed in the adhesive cementation of indirect restorations: A micro-Raman analysis. J. Dent. 2009, 37, 610-615. [CrossRef]

18. Tan, F.; Qiao, X.; Chen, J.; Wang, H. Effects of coupling agents on the properties of epoxy-based electrically conductive adhesives. Int. J. Adhes. Adhes. 2006, 26, 406-413. [CrossRef]

19. Chmielewska, B.; Czarnecki, L.; Sustersic, J.; Zajc, A. The influence of silane coupling agents on the polymer mortar. Cement Concr. Compos. 2006, 28, 803-810. [CrossRef]

20. Antonucci, J.; Dickens, S.; Fowler, B.; Xu, H.; Mcdonough, W. Chemistry of silanes: Interfaces in dental polymers and composites. J. Res. Natl. Inst. Stand. Technol. 2005, 110, 541-558. [CrossRef]

21. Liu, Q.; Ding, J.; Chambers, D.; Debnath, S.; Wunder, S.; Bran, G. Filler-coupling agent-matrix interactions in silica/polymethylmethacrylate composites. J. Biomed. Mater. Res. 2001, 57, 384-393. [CrossRef]

22. Praveen, B.; Babaji, H.V.; Prasanna, B.G.; Rajalbandi, S.K.; Shreeharsha, T.V.; Prashant, G.M. Comparison of Impact Strength and Fracture Morphology of Different Heat Cure Denture Acrylic Resins: An In vitro Study. JIOH 2014, 6, 12-16. [PubMed]

23. Zidan, S.; Silikas, N.; Alhotan, A.; Haider, J.; Yates, J. Investigating the Mechanical Properties of ZrO2-Impregnated PMMA Nanocomposite for Denture-Based Applications. Materials 2019, 12, 1344. [CrossRef] [PubMed]

24. Albaladejo, A.; Osorio, R.; Papacchini, F.; Goracci, C.; Toledano, M.; Ferrari, M. Post silanization improves bond strength of translucent posts to flowable composite resins. J. Biomed. Mater. Res. Part B Appl. Biomater. 2007, 82, 320-324. [CrossRef] [PubMed]

25. Brentel, A.; Özcar, M.; Valandro, L.; Alarca, R.; Bottino, M. Microtensile bond strength of a resin cement to feldpathic ceramic after different etching and silanization regimens in dry and aged conditions. Dent. Mater. 2007, 20, 677-686. [CrossRef]

26. Abboud, M.; Casaubieilh, L.; Morvan, F.; Fontanille, M.; Duguet, E. PMMA-based composite materials with reactive ceramic fillers: IV. Radiopacifying particles embedded in PMMA beads for acrylic bone cement. J. Biomed. Mater. Res. 2000, 53, 728-736. [CrossRef]

27. British Standards Institution. BS7448-1. Fracture Mechanics Toughness Tests. Method for Determination of KIc, Critical CTOD and Critical J Values of Metallic Materials. 1991. Available online: https://shop.bsigroup. com (accessed on 8 January 2020).

28. Piddock, V.; Marquis, P.M.; Wilson, H.J. Comparison of the strengths of aluminous porcelain fired on to platinum and palladium foils. J. Oral Rehabil. 1986, 13, 31-37. [CrossRef]

29. Adabo, G.; Dos Santos Cruz, C.; Fonseca, R.; Vaz, L. The volumetric fraction of inorganic particles and the flexural strength of composites for posterior teeth. J. Dent. 2003, 31, 353-359. [CrossRef]

30. Mortazavi, V.; Atail, M.; Fathi, M.; Keshavarzi, S.; Khalighinejad, N.; Badrian, H. The effect of nanoclay filler loading on the flexural strength of fiber-reinforced composites. Dent. Res. J. 2012, 9, 273-280.

31. Halvorson, R.; Erickson, R.; Davidson, C. The effect of filler and silane content on conversion of resin-based composite. Dent. Mater. 2003, 19, 327-333. [CrossRef] 
32. Ihab, N.; Hassanen, K.; Ali, N. Assessment of zirconium oxide nano-fillers incorporation and silanation on impact, tensile strength and color alteration of heat polymerized acrylic resin. J. Baghdad Coll. Dent. 2012, 24, $36-42$.

33. Fu, J.; Naguib, H.E. Effect of Nanoclay on the Mechanical Properties of PMMA/Clay Nanocomposite Foams. J. Cell. Plast. 2006, 42, 325-342. [CrossRef]

34. Shakeri, F.; Nodehi, A.; Atai, M. PMMA/double-modified organoclay nanocomposites as fillers for denture base materials with improved mechanical properties. J. Mech. Behav. Biomed. Mater. 2019, 90, 11-19. [CrossRef] [PubMed]

35. MC Nally, L.; O'Sullivan, D.J.; Jagger, D.C. An in vitro investigation of the effect of the addition of untreated and surface treated silica on the transverse and impact strength of poly(methyl methacrylate) acrylic resin. Bio-Med. Mater. Eng. 2006, 16, 93-100.

36. Anderson, T. Fracture Mechanics: Fundamentals and Applications; CRC Press: London, UK, 1995.

37. Engineered Materials Handbook; ASM International: Cleveland, OH, USA, 1988.

38. Cazzaniga, G.; Ottobelli, M.; Ionescu, A.C.; Paolone, G.; Gherlone, E.; Ferracane, J.L.; Brambilla, E. In vitro biofilm formation on resin-based composites after different finishing and polishing procedures. J. Dent. 2017, 67, 43-52. [CrossRef]

(C) 2020 by the authors. Licensee MDPI, Basel, Switzerland. This article is an open access article distributed under the terms and conditions of the Creative Commons Attribution (CC BY) license (http://creativecommons.org/licenses/by/4.0/). 